\title{
La mujer en la masonería madrileña entre 1869 y 1939
}

\section{Women's Masonry in Madrid from 1869 to 1939}

\author{
Manuel Según-Alonso \\ Universidad de Educación a Distancia, España \\ manuelsegun@gmail.com
}

Recepción: 17 de mayo de 2019/Aceptación: 10 de junio de 2019.

doi: https://doi.org/10.15517/rehmlac.v11i1.37197

Palabras clave

Masonería madrileña, feminismo, republicanismo, laicismo, logias madrileñas.

Keywords

Madrid freemasonry, feminism, republicanism, laicism, Madrid lodges.

Resumen

En el Madrid de finales del siglo XIX y primer tercio del siglo XX, en el marco del librepensamiento, el republicanismo y el discurso laicista, muchas mujeres buscan los principios de igualdad, fraternidad y libertad que la masonería defiende. A través de este trabajo, pretendemos recuperar la labor de masonería femenina madrileña y su contribución a la causa feminista, la emancipación de la mujer y al progreso. Trataré de recuperar el trabajo de todas las logias de Adopción y mixtas madrileñas, y el nombre de sus miembros.

\begin{abstract}
In Madrid during the late nineteenth-century and first third of the twentieth-century there were among the freethinking and republican circles, influenced by laicism, many women seeking the principles of freedom, equality and fraternity that Freemasonry defends. Through this work, we intend to recover the work done by women's Masonry in Madrid and its contribution to the feminist cause, the emancipation of women, and the progress of society as a whole. I aim to recover the work of all Adoption and mixed Lodges in Madrid and the name of their members.
\end{abstract}

\section{Introducción}

La mujer ha estado relegada a la esfera de lo privado y silenciada en un mundo dominado por una estructura patriarcal que supone un gran obstáculo para su desarrollo social, económico, político, intelectual y legal. Obstáculo que también se vive en el mundo masónico puesto que, sus reglamentos no permiten desde las constituciones de Anderson su presencia, lo que obliga a buscar una solución por aquellos miembros que no creen que haber nacido mujer sea un problema para ser iniciada. Esto no significa la aceptación de que trabaje a nivel de igualdad con el hombre y para evitar caer en la irregularidad, se crea una masonería 
especial, conocida como masonería de Adopción $^{1}$ que tiene un rito propio, el rito de Adopción.

La exclusión de la mujer se debe al hecho que, en ese momento, se considera que no cumple con el principio masónico de "ser libre y de buenas costumbres" ya que vive bajo la tutela masculina ${ }^{2}$. Así, ya entre 1725 y 1730 se encuentran afiliadas en asociaciones con características masónicas $^{3}$, no siendo hasta 1774 cuando el Gran Oriente de Francia crea el rito de Adopción, en el que se establece una serie de reglas que hace depender a las logias femeninas de una logia masculina ${ }^{4}$ y no de una Obediencia:

Todas las notabilidades de París en las ciencias, en las letras, en las artes y en la nobleza, acudían presurosas á la Logia de Adopción, fundada en 1760 por el Conde de Bernonville [...]. En 1775 la Logia Saint-Antoine, Or.. de París, fundó una Logia de Adopción, que fué presidida por la Duquesa de Borbón [...]. El Duque de Chartres, después Duque de Orleans, Gran Maestre de la Francmasonería francesa, presidió la solemne ceremonia. Entre las hermanas asistentes se contaban las Duquesas de Luynes y de Brancas; la Condesa de Caylus, la Vizcondesa Tavannes, y otras muchas hermanas de elevadísimo rango ${ }^{5}$.

En 1787 se imprime el primer manual “de la verdadera Masonería de Adopción”, que pronto, queda en desuso, restableciéndose en 1830 y reformado en $1861^{6}$. A partir de ese momento, la masonería femenina adquiere un acusado anticlericalismo, implicándose en las transformaciones sociales y políticas con la idea de lograr desvincular a la mujer del clero y la secularización de la sociedad ${ }^{7}$. No se puede olvidar que muchos masones consideran que la educación de la mujer y su emancipación logrará contrarrestar el poder de la Iglesia.

Por otra parte, la Ligue pour Le Droit des Femmes, fundada por León Richer y Marie Deraismes en 1882 en Francia, se convierte en referente de un feminismo posibilista. Esta liga defiende el ejercicio de los derechos civiles de la mujer, los derechos igualitarios dentro

\footnotetext{
${ }^{1}$ Natividad Ortiz Albear, "La integración de las mujeres en la masonería española a través del Rito de adopción (1868-1939)", Revista Studia Histórica. Historia Contemporánea 23 (2005): 133, http://revistas.usal.es/index.php/0213-2087/article/view/6024/6045

${ }^{2}$ Ortiz Albear, "La Logia Amor de Madrid: una logia femenina en la II República", en La masonería española en el 2000. Una revisión Histórica, coord. José Antonio Ferrer Benimeli (Zaragoza: Gobierno de Aragón, 2001), tomo II, 629.

${ }^{3}$ J. Ruiz “Alvar Fáñez” y C. Ruiz “Algebra”, en Estatutos y Reglamentos de la Masonería de Adopción (Madrid: Imprenta de Ricardo Rojas, s/f), 11.

${ }^{4}$ Ruiz y Ruiz, Estatutos y Reglamentos, 10-13; Janet Burke y Jacob Margaret, Les premiéres francs-maconnes au siécle des Lumiéres (Burdeos: Presses Universitaires, 2010); y Ortiz Albear, "Las Mujeres en la Masonería Española (1868-1939)", REHMLAC 4, no. 2, (diciembre 2012-abril 2013): 78, https://revistas.ucr.ac.cr/index.php/rehmlac/article/download/12185/11468/ y Libertad Morte, "La mujer en la masonería", Revista Historia 16 (noviembre de 1977): 21-25

${ }^{5}$ Histoire pittoresque de la Francmaçonérie et des sociétés sécrétes (París: 1844), 111 y siguientes en Ruiz y Ruiz, Estatutos y Reglamentos, 14.

${ }^{6}$ Ruiz y Ruiz, Estatutos y Reglamentos, 10,13.

${ }^{7}$ Ortiz Albear, "La Masonería Española", 135-136.
} 
del matrimonio, moralidad igualitaria, abolición de la prostitución, el derecho a la educación y la igualdad de retribución en el trabajo ${ }^{8}$.

En 1893, Maria Deraismes y George Martin fundan una nueva obediencia mixta denominada Derecho Humano (en adelante DH). En su constitución se puede leer: “[...] afirma la igualdad esencial de los dos seres humanos: el hombre y la mujer. Proclamando el Derecho Humano, la orden por la que ellos gocen, en la tierra, de igual forma, la justicia social en una humanidad organizada en sociedades libres y fraternales"9.

Se parte de la hipótesis de que la mujer en Madrid utiliza a la masonería como medio de incorporación a una sociedad profundamente dominada por el hombre y aunque mantiene una posición secundaria, ve en ella un lugar de libertad que le posibilita desarrollar sus aspiraciones intelectuales.

Se quiere responder a las siguientes preguntas: ¿se puede hablar de una masonería femenina en Madrid?, y si es así, ¿cuál es el papel real de la mujer dentro de la masonería entre 1869 y 1939?, ¿cuándo y por qué se incorpora a la masonería madrileña?, ¿qué ritos practica?, ¿qué temas trata?, ¿qué posicionamiento mantiene en relación con la Iglesia, la política o los temas relacionados con el feminismo?

\section{La masonería de Adopción en Madrid}

\section{La mujer en las logias de Adopción}

En España, el retraso del proceso industrializador, la ausencia de una verdadera revolución burguesa, el arraigado conservadurismo de las costumbres y la influencia de la Iglesia en la sociedad civil hacen que la mujer se incorpore tarde al mundo laboral retrasando el nacimiento de las reivindicaciones feministas que no verán la luz hasta la creación, bien entrado el siglo veinte, de la Asociación Nacional de Mujeres Españolas y la Cruzada de Mujeres Españolas que centran en el sufragio femenino sus reclamaciones políticas ${ }^{10}$.

Desde el punto de vista jurídico la mujer a finales del siglo XIX se mantiene sometida a la tutela masculina y el Código Civil de 1889 no le concede derechos. Es por ello, que su entrada en masonería es minoritaria, siendo, a partir del Sexenio Revolucionario, en Madrid, cuando aparecen las primeras mujeres en las logias y el periodo de 1870-1880 el momento clave para su desarrollo ${ }^{11}$. Así, la mujer que se atreve a romper los esquemas preconcebidos en una sociedad patriarcal quiere trabajar dentro de la Orden, lo mismo que lo hace en otros

\footnotetext{
${ }^{8}$ María José Lacalzada de Mateo, “La Mitad Femenina 'para' la masonería y 'en' masonería (1868-1936). Balance y perspectiva", Revista Investigaciones históricas: Época moderna y Contemporánea 23 (2003): 123, https://core.ac.uk/download/pdf/61558786.pdf

${ }^{9}$ Rosa Ballesteros García, "Las distracciones misteriosas: Colombine y la masonería portuguesa", Revista de Ciencias Sociales 5 (2005): 1-21.

${ }^{10}$ Ortiz Albear, Mujeres masonas en España (1868-1939) (Santa Cruz de Tenerife: Ediciones Idea, 2007), 2729.

${ }^{11}$ Ortiz Albear, "La Logia Amor de Madrid", 629.
} 
entornos de libertad, rompiendo estereotipos y siendo modelos de cambio ${ }^{12}$. Muchas de ellas están relacionadas con los movimientos librepensadores, anticlericales o sociedades espirituales como la teosofía ${ }^{13}$.

La masonería madrileña está muy influenciada por la masonería francesa, desarrollándose el rito, las cámaras y las logias de Adopción ${ }^{14}$ que nacen para evitar la irregularidad de las logias masculinas.

Como se verá, al tratar la masonería mixta en el último tercio del siglo XIX y hasta la regularización de las logias de Adopción, se encuentran mujeres, con frecuencia, en los cuadros de las logias masculinas lo que indica, sin reconocerlo, que muchas logias pasan a ser mixtas ${ }^{15}$. Aunque por la poca información que se conserva, no se puede afirmar, de forma rotunda, que estén al mismo nivel que los varones e incluso no se puede afirmar con seguridad en que rito son iniciadas, aunque como apunta Randouyer "caben muy pocas dudas de que la mayor parte de las mujeres que ingresaron en la Institución fueron iniciadas en el Rito Escocés Antiguo y Aceptado (REAA)"16.

La finalidad de la entrada de la mujer en masonería queda reflejada en la conmemoración del primer aniversario de la logia 5 de abril que tiene lugar en 1889 y en la que la masona Ángeles López de Ayala17 afirma que dignifica: "a la mujer elevándola al igual del hombre, y reconociéndola los derechos de la personalidad [...]. Se ha dado un gran paso hacia la emancipación de la mujer [...]; la Masonería será el redentor de nuestro sexo"18.

\footnotetext{
${ }^{12}$ Para conocer como es vista la mujer entre 1868 y 1920 por los masones ver: Jesús Espinosa Gutiérrez, "Feminismo de hombres en la masonería y el librepensamiento español (1868-1920)", en La masonería hispano-lusa y americana. De los absolutismos a las democracias (1815-2015), coord. José Miguel Delgado Idarreta e Yván Pozuelo Andrés (Oviedo: Universidad de Oviedo, 2017), tomo I, 149-162.

${ }_{13}$ Lacalzada de Mateo, "La Mitad Femenina 'para' la masonería", 122 y Ortiz Albear, "La Masonería Española", 133.

${ }^{14}$ Ortiz Albear, "La Logia Amor de Madrid”, 629-630.

${ }^{15}$ Se considera en este trabajo que cualquier logia masculina en la que hay presencia femenina, aunque no se reconozca de facto, pasa a ser mixta, y por tanto se estudiará en el apartado dedicado a este tipo de logias.

${ }^{16}$ Françoise Randouyer, "Presencia femenina precoz en las logias españolas (1868-1898)", en La masonería española en el 2000. Una revisión Histórica, coord. Ferrer Benimeli (Zaragoza: Gobierno de Aragón, 2001), tomo II, 625 .

${ }^{17}$ En 1888 ingresa en la logia de Adopción Amantes del Progreso y en 1889 en la logia Hijas de los Pobres. Es una de las exponentes de las doctrinas espiritistas de influencia deísta. Consta su afiliación en la logia Constancia núm. 102 de Barcelona como secretaria del taller, llegando a ser grado 30. Nace en Sevilla el 21 de septiembre de 1858 y muere en Barcelona el 29 de enero de 1926. Dramaturga, narradora, periodista y política republicana. Una de las principales feministas de finales del siglo diecinueve y principio del veinte. Fundadora de la Sociedad Autónoma de Mujeres de Barcelona (1892) y de la Sociedad Progresiva Femenina (1898). Defiende que la mujer debe emanciparse del hombre y de la Iglesia. $C D M H$ Masonería B 401/50, CDMH Teosofía 33/2588, y Ortiz Albear, Las Mujeres en la Masonería, 47-89 y 113-275, Vida Masónica, 4 (1926) 60-62.

${ }^{18}$ Ferrer Benimeli, Exposición: La masonería española. 1728-1939 (Alicante: instituto Juan Gil-Albert, Caja de Ahorros Provincial de alicante, Diputación de Alicante, 1989), 56 y Ferrer Benimeli, "Las mujeres y la masonería española en el siglo XIX. REHMLAC+ 10, no. 2 (diciembre 2018-mayo 2019): 162-163, https://revistas.ucr.ac.cr/index.php/rehmlac/article/download/12185/11468/
} 
O en los preliminares del "Ritual de Aprendiza Masona del Grande Oriente Español" (GOE) de 1906, en el que se da una explicación paternalista para justificar la admisión de la mujer en masonería:

Según las reglas inmutables de nuestra Orden, las mujeres no pueden ser admitidas en nuestras logias. Sin embargo, teniendo en cuenta que el bello sexo es una parte muy importante de la Humanidad, y que está dotado en general de cualidades y virtudes que deben ser premiadas, si no queremos ser injustos, algunos de nuestros hh. [...] fundar la MASONERÍA DE ADOPCIÓN, en donde aquel sexo, uniéndose por lazos fraternales y de una manera análoga al nuestro pudiera encontrar una ocasión más de ser útil a sus adeptos y a la fraternidad ${ }^{19}$.

A partir de 1890, aparecen los primeros reglamentos sobre el rito de Adopción. Su regulación se establece por primera vez en 1892, en el que se declara que no se puede iniciar, afiliar, regularizar ni conceder grados superiores a la mujer en rito diferente al de Adopción ${ }^{20}$. El último reglamento se publica en $1932^{21}$.

Para ser admitida en una logia de Adopción debe ser investigada, observar una conducta intachable, haber cumplido dieciocho años y tener medio de vida suficiente ${ }^{22}$. Además, si está embarazada no podrá recibir la iniciación hasta "su completo restablecimiento" ${ }^{23}$, necesitando el consentimiento de la persona de la que dependa:

Las casadas no recibirán la iniciación si no acompañan á la solicitud de ingreso autorización firmada por su marido; tampoco podrán obtener este favor las candidatas que estén bajo la potestad de otra persona, y no presenten al Taller el consentimiento escrito de la persona ó personas de quien dependa, según las leyes civiles. Las que estuvieren en pleno derecho de administrar sus bienes, los de sus maridos o los de sus hijos, exhibirán los documentos comprobatorios de este derecho ${ }^{24}$.

E incluso:

Las masonas solteras ó viudas que contraigan matrimonio, deberán presentar á su Taller dentro de los quince días siguientes á la celebración del matrimonio, autorización firmada por su marido para continuar en trabajos. Pasado este tiempo sin haber presentado dicho documento, serán baja temporalmente en la Orden, no

\footnotetext{
${ }^{19}$ Ritual de la aprendiza masona del Rito de Adopción. (Madrid: 1906), 1 en Ortiz Albear, "La Masonería Española", 138.

${ }^{20}$ Boletín Oficial del Gran Oriente Español (en adelante BOGOE), (15 de agosto de 1892).

${ }^{21}$ Ortiz Albear, "Las Mujeres en la Masonería", 81-82.

${ }^{22}$ Ruiz y Ruiz, Estatutos y Reglamentos, 3.

${ }^{23}$ Artículo XVII en Ruiz y Ruiz, Estatutos y Reglamentos, 22.

${ }^{24}$ Artículo XVIII en Ruiz y Ruiz, Estatutos y Reglamentos, 22-23.
} 
pudiendo ser recibidas en su Taller ni en ningún otro, y siendo consideradas como profanas hasta la presentación del permiso ó hasta el fallecimiento del marido ${ }^{25}$.

En 1921, el GOE tiene que abandonar la iniciación de la mujer como condición para ser admitidas en la Asociación Masónica Internacional, ingreso que no logra hasta años después. Teniendo que esperar a 1931 para volver a encontrar a la mujer en logias de Adopción madrileñas.

En 1932, los Estatutos del GOE, aunque sin admitir la igualdad del hombre y la mujer, inicia cierta apertura, probablemente debido a las concesiones que la Segunda República había establecido en defensa de los derechos civiles y políticos de la mujer, planteando al Supremo Consejo de Grado 33 la adaptación de las normas masónicas a los cambios producidos en la sociedad española.

\section{Las cámaras y las logias de Adopción madrileñas}

El anuario de 1895 del GOE recoge siete logias de Adopción en España ${ }^{26}$. Entre ellas cita en Madrid a la logia Hija de los Pobres $^{27}$ aunque con anterioridad existen otras:

Logia de Adopción Minerva. Una de las primeras logias de Adopción que se constituyen en España. Fundada en 1873, auspiciada por la logia Porvenir. Según el boletín del Gran Oriente de España: "cuenta con un número respetable de señoras, esposas en su mayor número de hermanos nuestros, y se distingue por la seriedad de sus trabajos". Entre sus miembros se encuentra la actriz Esmeralda Cervantes ${ }^{28}$, nombre artístico de Clotilde Cerdá Bosch en $1880^{29}$.

\footnotetext{
${ }^{25}$ Artículo XXVIV en Ruiz y Ruiz, Estatutos y Reglamentos, 26.

${ }^{26}$ Ferrer Benimeli, Exposición: La masonería española, 56.

${ }^{27}$ Centro Documental de Memoria Histórica (en adelante CDMH) Masonería A 734/17.

${ }^{28}$ Nace en Barcelona el 28 de febrero de 1861 y muere en Santa Cruz de Tenerife el 12 de abril de 1926. Concertista de arpa. Hija de Ildefonso Cerdá, responsable del ensanche de Barcelona y de la pintora Clotilde Bosch. Estudia pintura con Mariano Fortuny, pero se decanta por la música. En 1865 es una de las principales impulsoras del movimiento antiesclavista. Debuta en el Teatro Imperial de Viena en 1873. El rey envía al conde Morphy a Barcelona para que clausure la academia de Ciencias, Artes y Oficios de la Mujer, desde donde pregona sus ideas. En 1885, en Barcelona participa en la creación de la institución educativa femenina denominada Acadèmia per la Ilustració de la Dona que se cierra por falta de apoyo. Boletín Oficial del GODE (no. 42, 1880), 624 en Ortiz Albear: Las mujeres en la Masonería, 96, El Mundo (1 de agosto de 2017), Gran Logia Femenina de Francia, https://web.archive.org/web/20081117191120/http://www.glff.org/internet/sp/histd.htm

${ }^{29}$ Boletín Oficial del Gran Oriente de España, 42 (1880) en Ortiz Albear, "Las mujeres en la Masonería", 96 y Ferrer Benimeli, "Las mujeres y la masonería", 169.
} 
Logia de Adopción Hijas de los Pobres. Pertenece a la Gran Logia Unida de España ${ }^{30}$. Se funda el 27 de noviembre de 1887. La venerable maestra es Suceso Sánchez Martín ${ }^{31}$.

Logia Hijas del Sol. Nace sobre 1872, asociada a la logia Hijos del Trabajo. Su objetivo es la educación de la mujer para apartarla del fanatismo, la caridad y la beneficencia. Tiene un órgano de prensa dirigido por la Baronesa de Wilson ${ }^{32}$. Randouyer señala que no puede considerarse una logia de Adopción, sino una asociación femenina laica con fines progresistas ${ }^{33}$.

Logia Hijas de Memphis. Taller que trabaja entre 1877 y 1880, formado por catorce masonas. La correspondencia es suscrita directamente por ella, sin pasar por ninguna logia masculina, lo que le lleva a Randouyer a concluir que estamos en un caso precoz de logia femenina que rige por sí sola ${ }^{34}$ e incluso Ferrer Benimeli afirma que tampoco pertenece a ninguna obediencia ${ }^{35}$.

Hijas del Progreso pertenece al GOE. Trabaja entre 1888 y $1898^{36}$.

Hijas del Sol de la Obediencia GODE. Tenemos datos de $1872^{37}$.

Porvenir. Trabaja al menos en 1890. A esta logia pertenece la condesa de Chinchón, una prima de Alfonso XII cuyo nombre no se cita, Isabel Gorowsky y Borbón, y Rosario Acuña ${ }^{38}$.

La logia Ibérica no. 7 trabaja por la integración de la mujer en la masonería. En 1890, inicia a dos mujeres, señalando en dicho acto que "adelante, pues, en breve veremos en activo las logias de señoras, tan necesarias a los fines de la Orden"39.

La logia El Progreso núm. 88 mantiene una cámara de Adopción en la que entre 1891 y 1894 se encuentran cinco mujeres: María Obispo Hernanz, simbólico Soledad; Juliana Susana Dupont Seivert, simbólico Juana Achette; Juliana de Arco; Natividad López de Polo, simbólico Juana de Arco que también se encuentra en la logia hijos del Trabajo de Valdemorillo (Madrid) y es esposa del masón Miguel Polo de Castells; Basilia Pérez Alemán,

\footnotetext{
${ }^{30}$ CDMH Masonería A 734/17.

${ }^{31}$ Simbólico Rebeca. Grado 18. Forma parte de la logia Legalidad en diciembre de 1886. También está afiliada a las logias Lealtad e Hijas de los Pobres. Datos masónicos entre 1886-1889. CDMH Masonería A 734/17.

32 Ortiz Albear, "Las mujeres en la Masonería", 94.

${ }^{33}$ Randouyer, "Presencia femenina", 608.

${ }^{34}$ Randouyer, "Presencia femenina”, 609.

${ }^{35}$ Ferrer Benimeli, "Las mujeres y la masonería", 170.

${ }^{36}$ Lacalzada de Mateo, "La Mitad Femenina 'para' la masonería”, 129.

${ }^{37}$ Lacalzada de Mateo, "La Mitad Femenina 'para' la masonería”, 129.

${ }^{38}$ Latomia, 1 (1931), 204.

${ }^{39}$ BOGOE (9 de noviembre de 1890).
} 
simbólico Actividad, que nace en Vélez-Málaga en 1859; y Regina Pérez Alemán, simbólico Rectitud, que nace en Murcia en $1863^{40}$.

\section{Cuadro 1}

Cámara de Adopción de la logia El Progreso no. $88^{41}$

\begin{tabular}{|l|l|l|l|l|l|l|}
\hline Apellidos & Simbólico & Profesión & F/N & Años & Iniciación & Grado \\
\hline Obispo Hernanz, María & Soledad & Su sexo & & 1892 & & MP \\
\hline Dupont Seivert, Juliana Susana & Juana de Arco & & & 1894 & $02 / 01 / 1894$ & Low \\
\hline López de Polo, Natividad & Juana de Arco & & & $1892-1893$ & & 1 \\
\hline Pérez Alemán, Basilia & Actividad & Su sexo & 1859 & 1891 & $19 / 10 / 1891$ & 1 \\
\hline Pérez Alemán, Regina & Rectitud & Su sexo & 1863 & 1891 & $19 / 10 / 1891$ & 1 \\
\hline
\end{tabular}

Pero hay madrileñas que trabajan en logias de otras regiones. Es el caso de la madrileña Patrocinio Palarea de Soto, grado tercero, que se afilia en la logia Alona núm. 44 de Alicante en 1877 y que afirma haber sido iniciada en 1873. El 15 de febrero de 1886, se inicia en la misma logia, Rosario de Acuña y Villanueva, simbólico Hipatia, nacida en Madrid el 1 de enero de 1850 y muerta en Gijón el 5 de mayo de 1923; su iniciación se saltan los trámites debido a "su conocida personalidad y brillantes servicios a la causa del progreso" 42 .

A partir de 1891, el Gran Oriente Nacional de España (en adelante GONE) y en 1892, el GOE publican sus reglamentos sobre las logias de Adopción, en un intento de acabar con la presencia de la mujer en logia en igualdad de condiciones que el hombre ${ }^{43}$.

Con el inicio de la crisis finisecular y a partir de 1896, la masonería femenina madrileña como el resto de la Orden, desaparece casi completamente, no siendo hasta entrado el siglo veinte cuando se vuelve a encontrar mujeres en logia, concretamente, en la logia Ibérica.

La primera masona iniciada en Madrid en el siglo veinte es Quintina Márquez Calcerrada, lo hace en la logia Ibérica en 1901, de personalidad comprometida con el pensamiento anticlerical. Se vuelve a encontrar en una tenida organizada por la logia Catoniana el 9 de abril de $1915^{44}$.

Ese mismo año, se celebra una velada masónica que organiza el Gran Consejo en honor de un grupo de señoras anticlericales. A ella y a otra en la logia Catoniana, asisten las

\footnotetext{
${ }^{40}$ Manuel Según Alonso, "Masonería y política en Madrid 1900-1939” (Tesis de Doctorado en Historia, UNED, Madrid, 2018), anexo 3.

${ }^{41}$ CDMH Masonería A 546.

${ }^{42}$ CDMH Masonería A 576/1 y 3 y CDMH Masonería A 571/2 en Vicent Sampedro Ramo, "La aplicación de la ley sobre represión de la Masonería y del Comunismo en el país valenciano: Los Masones de Alicante y Castellón (1938-1963)" (Tesis de doctorado en historia, Universitat Jaume I de Castellón de la Plana, 2016), 289-291.

${ }^{43}$ Ferrer Benimeli, "Las mujeres y la masonería", 176.

${ }^{44}$ CDMH Masonería A 550/2, CDMH Masonería A 550/22, CDMH Masonería A 564/1.
} 
masonas de la cámara de Adopción de la logia Ibérica ${ }^{45}$ : Quintina Márquez, Consuelo Álvarez Pool ${ }^{46}$, Otilia Solera García ${ }^{47}$ y Ana Ferrer García ${ }^{48}$.

El 14 de agosto de 1907 hay dos peticiones de ingreso, pero sólo María Payá es iniciada $^{49}$. El 11 de octubre de 1913 se celebra una tenida blanca en la logia Ibérica para la adopción de lowetones y lowetonas ${ }^{50}$. Además, parece las propuestas de iniciación de María Bueno Núñez de Prado, Lydia Etaya Las Peñas, Valeriana Pérez Reguero y Dolores Hernández Traverso, de las que no se sabe si finalmente son iniciadas ${ }^{51}$.

\section{Cuadro 2}

Cámara de Adopción de la logia Ibérica entre 1900 y $1923^{52}$

\begin{tabular}{|l|l|l|l|}
\hline Apellidos & Simbólico & Profesión & Años \\
\hline Álvarez Pool, Consuelo & Costa & Telegrafista & $1907-1915$ \\
\hline Azcárate Álvarez, Esther & & Telegrafista & 1915 \\
\hline Duch Martín, Antonia & Rosario de acuña & Su sexo & $1914-1915$ \\
\hline Fernández Traverso, Dolores & & Pensionista & 1915 \\
\hline Ferrer García, Ana & Emma & Su sexo & 1907 \\
\hline Gallego Bravo, Orencia & Concepción Arenal & Su sexo & $1915-1916$ \\
\hline Hurlé Suárez, Celia & Carlota Corday & Su sexo & $1914-1923$ \\
\hline Jaime Martínez, Pilar & Madame Rolland & Empleada & 1914 \\
\hline Márquez Calderrada, Quintina & Mariana Pineda & Su sexo & $1901-1917$ \\
\hline Payá y Enrique, María & & Modista & - \\
\hline Solera García, Otilia & Luisa Michel & Modista & $1907-1915$ \\
\hline
\end{tabular}

${ }^{45}$ CDMH Masonería B, 239/32, CDMH Masonería A 51/751, BOGOE (26 de febrero de 1907), CDMH Masonería A 726/1.

${ }^{46}$ Simbólico Costa, pertenece a la logia Ibérica núm.7, datos entre 1910-1915. Nace en Barcelona el 24 de julio 1867. Aprueba las primeras oposiciones a telegrafistas femeninas que se celebran en 1909, aunque en 1885 había aprobado el ingreso como auxiliar temporera. Es escritora, periodista, feminista y asidua participante en las conferencias y tertulias del Ateneo de Madrid. Colabora con el periódico El Progreso de Oviedo y el País de Madrid. Utiliza el seudónimo de Violeta. Pertenece a la generación femenina del 98. En 1909, crea la asociación las Damas Rojas de Madrid y forma parte de la Agrupación Socialista. En 1915, es parte del gabinete de prensa de la dirección General de Comunicaciones y en 1931 de la junta Consultiva del Cuerpo de Telégrafos. Se jubila en julio de 1932 y muere en Madrid en 1957. CDMH Masonería A 751/51; CDMH Masonería A 550/24; CDMH Masonería A 550/1; CDMH Masonería B 329/31; Natividad Ortiz Albear, Las mujeres en la Masonería (Málaga, Atenea, 2005), 107; Manuel Según Alonso, "Masonería y política en Madrid 1900-1939" (Tesis de Doctorado en Historia, UNED, Madrid, 2018), anexo 3.

${ }^{47}$ Simbólico Luisa Miguel, logia Ibérica. Presenta solicitud de iniciación el 15 de julio de 1907, aunque finalmente se inicia en 1911. Datos entre 1907-1915. Nace en Ávila el 22 de noviembre de 1880, soltera, modista. $C D M H$ Masonería B 239/30, CDMH Masonería A 550/1, CDMH Masonería A 751/51, CDMH Masonería A 550/24, CDMH Masonería A 550/22, BOGOE (27 de abril de 1911).

${ }^{48}$ Simbólico Emma. Iniciada en la cámara de Adopción de la logia Ibérica el 26 de septiembre de 1912. Inspectora de la logia de Adopción Paz en 1916, grado 3. Datos 1912-1916. Nace el 31 de marzo de 1864 en Valencia, casada, profesión "su sexo". CDMH Masonería B 239/34, CDMH Masonería A 726/1.

49 BOGOE (25 de octubre de 1907).

${ }^{50} \mathrm{CDMH}$ Masonería A 550/2.

${ }^{51} C D M H$ Masonería B 305/9, CDMH Masonería B 347/34, CDMH Masonería B, 723/15, CDMH Masonería A $179 / 19$.

${ }^{52}$ CDMH Masonería A 550. 
El 3 de mayo de 1916 se constituye la logia de Adopción Paz núm. 8 dependiente de la logia Ibérica ${ }^{53}$. En 1918, asisten al banquete solsticial ${ }^{54}$ al que también asisten otras señoras no masonas que forman parte de la Sociedad "Fraternidad Cívica" celebran un acto en el cementerio civil por el aniversario del fallecimiento de su venerable maestra Quintina Márquez y presidenta de la Sociedad. En esta logia encontramos a Consuelo Álvarez Pool, Antonia Dusch Martín ${ }^{56}$, Herminia Fanego Márquez ${ }^{57}$, Ana Ferrer García, Orencia Gallego Bravo ${ }^{58}$, Ana García Ferrera, Celia Hurle Suárez ${ }^{59}$, Pilar Jaime Martínez ${ }^{60}$, Clotilde Picot Bernabé ${ }^{61}$, Otilia Solera García y Francisca de la Torre ${ }^{62}$.

A partir de 1920, la mujer comienza a participar en movimientos políticos. Merece destacar su posicionamiento ante el sufragio femenino, donde algunas de ellas, tendrán una importancia sobresaliente. Ejemplos se encuentran en la Asociación Nacional de Mujeres Españolas; La Unión de Mujeres Españolas dirigida por la escritora, María Lejárraga ${ }^{63}$; la Cruzada de Mujeres Españolas y la Liga Internacional de Mujeres Ibéricas e Hispanoamericanas, presididas por la masona madrileña Carmen de Burgos Seguí64; masona

${ }^{53}$ CDMH Masonería A 735/25.

${ }^{54}$ BOGOE (31 de mayo de 1918).

${ }^{55}$ Nace el 7 de marzo de 1916 y desaparece en 1936. La idea es de la viuda de Nicolás Salmerón, Catalina García que quiere unir a todas las familias que tienen enterrados familiares en el cementerio Civil que en ese momento no tenía agua. Sus presidentas honorificas son Catalina García, viuda de Salmerón, Leonor Pi, viuda de la Guardia, y Consuelo Álvarez. La presidenta es Rosario Mea, viuda de Maher; vicepresidentas Catalina Salmerón García, Petra Ambite de Ayuso; tesorera, Rosa Cabrera de Ibarra; secretaria Otilia Solera, además diez vocales, una comisión ejecutiva, compuesta de tres inspectoras, y del asesor, Miguel Morayta y Sagrario. El País, El Heraldo, La Nación, El Sol, (7 de marzo de 1916); Heraldo de Madrid, (7 de agosto de 1923).

${ }^{56}$ Simbólico Rosario Acuña, logia Ibérica. Iniciada en marzo de 1915. Hija de masón. Grado primero. Nace en Madrid, profesión "su sexo". CDMH Masonería A 550/22, CDMH Masonería B 693/6, BOE (10 de marzo de 1945), Oliva Salmón Moviola, Los masones de Madrid (1939). Repertorio de miembros, acción cultural y comunicación social (La Laguna, Editorial Relax Color (CD), 2006), 124.

${ }^{57}$ Iniciada en la cámara de Adopción de la logia Ibérica. Profesión "su sexo". Ortiz Albear, Las mujeres en la Masonería, 109.

${ }^{58}$ Simbólico Concepción Arenal, logia Ibérica, y logia Paz. Iniciada el 1 de febrero de 1915. Grado primero. Datos 1915-1916. Profesión sus labores. CDMH Masonería A 179/13.

${ }^{59}$ Simbólico Carlota Gorday, logia Ibérica, iniciada el 11 de marzo de 1914, grado 1. Datos 1914-1923. Nace en Gijón el 12 de febrero de 1873, profesión "su sexo". CDMH Masonería B 286/31, BOE (18 de abril de 1945), BOSCG 33 (marzo y abril de 1923), CDMH Masonería A 564/1, CDMH Masonería A 550/22, CDMH Masonería A 286/31.

${ }^{60}$ Simbólico Madame Rolland, cámara de Adopción de la logia Ibérica, iniciada el 1 de abril de 1914, grado primero. Datos 1914-1915. Empleada. CDMH Masonería B 286/30, CDMH Masonería A 550/22, CDMH Masonería A 564/1.

${ }^{61}$ Iniciada en 1920 en la cámara de Adopción de la logia Ibérica. Ortiz Albear, Las mujeres en la Masonería, 109.

${ }^{62}$ BOGOE (1 de mayo de 1918). Muere el 12 de mayo de 1917 según datos de la lápida que se conserva en el cementerio Civil de Madrid.

${ }^{63}$ Acusada de masonería por el TERMC, pero sin pruebas, se archiva el expediente. Rosa Aragüés, "Victoria Kent y el Tribunal de Represión de la Masonería y el Comunismo", en La masonería hispano-lusa y americana, tomo II, 900-901.

${ }^{64}$ Simbólico Colombine, fundadora de la logia Amor y su primera Gran Maestra. Se inicia en el Gran Oriente Argentino y estuvo afiliada al Gran Oriente Lusitano Unido. Desde su posición de periodista se preocupa por 
que organiza la primera manifestación en las calles de Madrid para pedir el sufragio femenino ${ }^{65}$.

En 1920, la logia Ibérica tiene tres mujeres en la cámara de Adopción: Herminia Fanego Márquez, Francisca de la Torre y Clotilde Picot Bernabé, lo que indica que la logia Paz ha desaparecido ${ }^{66}$. A partir de este momento y hasta la llegada de la Segunda República no consta la iniciación, ni siquiera la pertenencia de ninguna mujer a la masonería de Adopción en Madrid.

En la Revista Vida Masónica encontramos en los últimos años de la dictadura varias biografías sobre masonas y artículos en defensa la igualdad entre masones y masonas especialmente por los masones madrileños León Cervera Cremades y Enrique González Linera. León Cervera defiende en julio de 1926 que ha llegado el "momento de la vida de los pueblos en que la mujer participa con una actividad que nadie puede desconocer ni impedir y en esta nueva actividad debiera encauzarse en las corrientes de las logias, que se dirigen hacia la cumbre del Bien, de la Belleza y del Amor fraternal" 67.

Con la segunda república la masonería femenina madrileña resurge. La presencia de la mujer sigue siendo pequeña, pero encontramos una importante presencia de escritoras, periodistas o $\operatorname{artistas}^{68}$. Como en el caso de los masones, muchas tienen un importante papel político, siendo miembros de los partidos republicanos. No tienen una voz unánime en el tema del sufragio femenino; así Carmen Burgos o Clara Campoamor, lo defienden sin fisuras; mientras que otras masonas son contrarias, como la radical socialista y periodista Rosario Cuarteto García ${ }^{69}$.

A pesar de los cambios, la mujer sigue siendo aceptada en las cámaras o logias de Adopción ${ }^{70}$ pero con algunas novedades, sobre todo en lo referente a su consideración social, lo que conlleva al reconocimiento de las limitaciones que ofrece el rito de Adopción y la necesidad de superarlo:

\footnotetext{
la emancipación de la mujer. En 1920 funda la Cruzada de Mujeres Españolas desde donde trabaja por el sufragio femenino y el pacifismo. Durante la República se afilia al Partido Republicano Radical Socialista. Fallece el 17 de octubre de 1932, siendo enterrada en el cementerio Civil de Madrid. CDMH Masonería A 566/2, CDMH Masonería B 580/32, CDMH Masonería A 8/5, Ortiz Albear, Las mujeres en la Masonería, 118120, Ortiz Albear, "La Logia Amor de Madrid", 637-638, Pilar Folguera Crespo, "Las mujeres en la España contemporánea", en Historia de las Mujeres en España (Madrid: Síntesis, 1997), 474-475.

${ }^{65}$ Ortiz Albear, "Las Mujeres en la Masonería", 80.

${ }^{66}$ Ortiz Albear, "Las mujeres en la Masonería", 109.

${ }^{67}$ Vida Masónica, 5 (julio de 1926), 72-73.

${ }^{68}$ Ortiz Albear, "Las mujeres en la Masonería”, 112.

${ }^{69}$ Simbólico Ariadna, pertenece a la logia Amor desde el mismo día de su instalación, escribe trabajos masónicos que firma con su simbólico en el BOGLE en los meses de enero y febrero de 1933, titulados "Ariadna" e "Igualdad de derechos". Oficinista y periodista. Pertenece al Partido Izquierda Radical Socialista. Contraria al sufragio femenino. BOGLE (marzo-abril 1933), CDMH Masonería A 566/2, CDMH Masonería B 143/14, Ortiz Albear, Las mujeres en la Masonería. 120-121 y Ortiz Albear, "La Logia Amor de Madrid", 638. ${ }^{70}$ Estatutos y Reglamento Generales del Grande Oriente Español (Sevilla: tipografía Minerva, 1932): 244-248.
} 
En España, habiéndose concedido a la mujer en lo profano los mismos derechos civiles y políticos que al hombre, tenemos el deber los masones de trabajar cerca de los organismos que pueden establecer leyes universales sobre la Masonería del Rito escocés [...] para que se modifiquen nuestras leyes rituales, en el sentido de que reconozcan a la mujer [...] iguales derechos y deberes que al hombre ${ }^{71}$.

En tanto llega ese momento: "forzoso será acomodarse a lo establecido en estos rituales".

En la Gran Logia Española (GLE) hay intentos de cambiar la situación de la mujer que se concreta en varias propuestas presentadas a la AMI. En varias asambleas de esta organización se lleva la cuestión, sin ser debatida y relegando las propuestas a ser consideradas con posterioridad ${ }^{72}$.

El posicionamiento de la GLE con respecto a la participación femenina en masonería le lleva en diciembre de 1931 a la instalación de la logia de Adopción Amor dependiente de la logia Mantua. Logia que representa la tendencia emancipadora de la mujer. En su primera tenida, se afilia Carmen de Burgos que es su venerable maestra y se inician Gloria Carbonell, María Álvarez de Burgos ${ }^{73}$, Mercedes Fernández, Catalina de Burgos Seguíi ${ }^{74}$, Elena Fojó Márquez y María Gutiérrez ${ }^{75}$.

Esta Logia se presenta como un espacio de reivindicación desde una perspectiva masónica rompiendo con el yugo de la iglesia y de la sumisión al varón:

Ya no significareis solamente para el hombre el objeto exclusivo de sus placeres y la esclava sumisa de sus pasiones [...], ni las anacrónicas figuras ascéticas y monjiles, que por los nefastos confesionarios [...], buscando una inútil contrición que para nada necesitan y las aparta constantemente de su verdadero objetivo en la vida social ${ }^{76}$.

\footnotetext{
${ }^{71}$ Ritual de la aprendiza masona del Rito de Adopción del GOE (Madrid: 1932), 4 en Ortiz Albear, "La Masonería Española", 139-140.

${ }^{72}$ CDMH Masonería A 562 y Ortiz Albear, "La Masonería Española", 140.

${ }^{73}$ Iniciada en la logia de Adopción Amor el 2 de diciembre de 1931, grado tercero. Actriz y escritora. Hija de Carmen de Burgos. Nace en Almería el 6 de noviembre de 1895 y muere en Madrid en 1939. BOGLE abrilmayo 1932, CDMH Masonería B 447/2, BOE, 20 de mayo de 1945, BOGLE abril/mayo 1932, Antonio Sevillano, "Catalina de Burgos, Báculo de Colombine", Revista Colombine. Agrupación Especial Carmen de Burgos del Ateneo de Madrid (2019): 1-5.

${ }^{74}$ Hermana de Carmen de Burgos y su mano derecha, nace en Almería en 1878 y muere en Madrid el 3 de mayo de 1964. Iniciada en 1931 durante el acto de la instalación de la logia y en 1934 figura como Gran Maestra. CDMH Masonería A 566/2, BOGLE (noviembre-diciembre de 1931), 12, CDMH Masonería B 446/64, AHD Madrid Sumario 31087 Legajo 1985, Ortiz Albear, Las mujeres en la Masonería, 120, Sevillano, "Catalina de Burgos, Báculo de Colombine", 1-5.

${ }^{75}$ La GLE da importancia a la creación de esta logia de Adopción, BOGLE (noviembre-diciembre de 1931): 124 y $C D M H$ Masonería A 566/2.

${ }^{76}$ BOGLE (noviembre-diciembre de 1931): 124 y CDMH Masonería A 566/2.
} 
El 17 de febrero de 1932, una logia del GOE del que no consta el nombre se dirige a la Respetable Logia de Adopción Amor para felicitarle por su nacimiento:

En adelante, habréis de ser portavoz de las ansias liberales de la mujer española, rompiendo con la odiosa tradición que la ha tenido sumida en una profunda inactividad y despego por la cosa pública [...]. Vuestra misión es ya otras; laborar con nosotros por la perfección humana, liberar su prejuicios y fanatismos a las profanas, difundir nuestros sublimes principios entre ellas, infiltrando en sus corazones al amor fraternal y la práctica de las virtudes, encaminado todo ello el mayor progreso cultural de la Patria para hacerle entregar serena y consciente en el concierto de los pueblos libres ${ }^{77}$.

En el mismo sentido, el 18 de febrero de 1932 la logia Mantua núm. 31 recibe una plancha de otra logia del GOE del que tampoco consta el nombre, en el que afirma en relación con la creación de la logia Amor: "[...] vendrá a despertar a la mujer española de su indiferencia e inactividad, incorporándole al seno de la Francmasonería, para que nos ayude la obra de fraternidad y regeneración humana"78.

En el BOGLE, durante los años 1932 y 1933 encontramos artículos escritos por mujeres de este taller que ponen de manifiesto su postura y en la que crítica cualquier tipo de marginación. Destacamos dos artículos que enmarca su posicionamiento sobre el tema de la Mujer.

El primero es el artículo de Consuelo Berges Rábago ${ }^{79}$ de 1932 que defiende la igualdad de la mujer en todos los campos asegurando que, si la República promete la igualdad de sexos, la masonería no puede ser $\operatorname{menos}^{80}$ :

[...] reclamaré siempre la reivindicación del sexo femenino dentro de la Masonería. Creo que nuestra progresiva y justiciera Institución no puede hoy, sin merma de su crédito, mantenerse al margen y mucho menos en contra del avance arrollador de las reivindicaciones femeninas, no sobre los hombres, no frente a los hombres, sino al lado de los hombres [...] porque no es verosímil que mujeres normales, conscientes

\footnotetext{
${ }_{77}$ CDMH Masonería A 355/2.

${ }^{78}$ CDMH Masonería A 355/2.

79 Simbólico Yasnaia, logia Amor. Año 1932. Nace en Ucieda (Cantabria) en 1899. Estudia en la escuela Normal de Maestras que sigue los métodos de la Institución Libre de Enseñanza. Es articulista en El Sol de Madrid y la Nación de Buenos Aires. Emigra a Perú en 1926, viajando por América Latina, y dirigiendo la revista Cantabria en Argentina y colaborando con la Institución Cultural Española. Vuelve a Madrid en 1931. En 1939 se exilia en Francia. Muere en 1988. BOGLE (agosto-septiembre de 1932), 18, BOSCG33 (diciembre de 1932), Francisco Ferrari Billoch, Entre masones y Marxistas. Revelación de la masonería femenina (Madrid: Ediciones Españolas, 1939), 85, Ortiz Albear: "Clara Campoamor y la logia Reivindicación de Madrid", 867. ${ }^{80}$ BOGLE (agosto-septiembre de 1932).
} 
y celosas de su dignidad colectiva de sexo, se avengan [...] a colaborar con la Masonería sin que ésta les asigne las armas necesarias para ${ }^{81}$.

El segundo, es un artículo de 1933 en el que se defiende, al igual que en el anterior, que la mujer deber estar en igualdad con el hombre:

La Masonería que es toda justicia y toda bondad, no puede hacer diferencias entre las dos mitades del género humano. Porque la mujer ha elevado hoy su nivel moral tan alto como el hombre [...] la utilidad de la mujer en la Masonería puede ser importantísima. [...]. Pero para ello es necesario que a la mujer se le dé toda la importancia que tiene, toda la consciencia que debe tener. Sin eternas tutelas ni adopciones que la esclavizan, la empequeñecen y la acostumbran a ser irresponsable ${ }^{82}$.

La logia Amor, además de reivindicar la emancipación de la mujer y de huir del clericalismo, realiza actividades de beneficencia ${ }^{83}$ y a favor del pacifismo:

Carmen de Burgos, propone la celebración de una manifestación mundial a celebrar los días 29 y 30 de julio de 1932 en Madrid, con el lema "No More War"84.

Elaboran un festival con el fin de recaudar fondos para repartir entre las familias pobres por Navidad ${ }^{85}$.

El exmasón y antimasón Ferrari Billoch reproduce una plancha de mayo de 1933 de la logia Amor solicitando ayuda para la masona Isabel Huelgas ${ }^{86}$.

La logia Amor tiene problemas económicos como muestra que el 7 de junio de 1932, la GLE recuerda a la logia Mantua núm. 31 que su logia de Adopción no paga los gastos del local donde celebran las tenidas ${ }^{87}$. La logia Amor pide a la logia Mantua que colabore con los gastos, puesto que ante su silencio "le ha obligado a tener que autofinanciarse desde el día de su instalación" 88 .

En la Gran Asamblea de la GLE de 1933, se presenta una proposición de la logia Mantua en nombre de la logia Amor sobre los derechos de la mujer en la que se pide: "la autonomía para las logias femeninas y una equiparación a los hombres en cuanto a los signos

\footnotetext{
${ }^{81}$ BOGLE (agosto-septiembre de 1932).

${ }^{82}$ BOGLE (marzo-abril de 1933).

${ }^{83}$ Boletín Secreto de la GLE, 2, 10 en Ortiz Albear, "Las mujeres en la Masonería”, 123.

${ }^{84}$ Ortiz Albear, "La Logia Amor de Madrid”, 637.

${ }^{85}$ Boletín Secreto de la GLE, 2, 10 en Ortiz Albear, "Las mujeres en la Masonería”, 123.

${ }^{86}$ Ferrari Billoch, Entre masones y Marxistas, 229.

${ }^{87}$ CDMH Masonería A 566/2.

${ }^{88}$ Ortiz Albear, "La Logia Amor de Madrid”, 635.
} 
de los grados", propone que en los Conventos Internacionales la GLE 1leve: "un voto siempre tendente a favorecer cualquier propuesta sobre igualdad de derechos de la mujer dentro de la masonería" 89.

En 1934 hay unas planchas de felicitación del año a la logia Constancia núm. 89 y Perseverancia núm. 70. En ellas se envía el cuadro de la logia en la que consta como venerable maestra Catalina de Burgos, inspectora Mercedes de Burgos, depositaria María Gutiérrez Ríos, oradora Andrée de Lissarrague, secretaria Ana Fiorini de Guzmán, maestra de Ceremonia Eulalia Taboada, maestra adjunta Blanca Alonso López, tesorera Celia Álvarez de Ferrer y limosnera Jane Blanc Borel ${ }^{90}$.

En el expediente de la logia Amor no aparece referencia al abatimiento de Columnas, pero en un certificado expedido por el Gran Secretario de la GLE de fecha 24 de septiembre de 1936 se afirma que: "[...] una de las hermanas de la logia Amor, Eulalia Taboada Diez de Tejado se encuentra 'en sueños' [...], no por causas imputables a ella, sino porque la logia Amor ha abatido columnas"

Por último, no se quiere olvidar, el caso de la masona y miembro de la logia Amor, Hildegart Rodríguez Carballeira, hija de Aurora Rodríguez Carballeira, también masona. Aurora educa a su hija como un ideal de mujer destinada a regenerar la sociedad convirtiéndose en una niña prodigio. El mismo padre de Hildegart es elegido por Aurora como un perfecto "semental" para sus fines. Cuando Hildegart quiere independizarse del influjo de su madre y ser dueña de su vida, ésta no lo acepta y la asesina el 9 de junio de 1933. Es enterrada en una fosa común en el cementerio civil de Madrid. El caso tiene mucha repercusión en la época y aún aparece en medios de comunicación como un experimento de creación de "un ser humano a medida"92.

${ }^{89}$ BOGLE (junio de 1933).

${ }^{90}$ CDMH Masonería A 566/2.

${ }^{91} \mathrm{CDMH}$, Masonería B, 551/54.

92 Nuevo Mundo (16 de junio de 1933), La Vanguardia, edición digital. http://www.lavanguardia.com/hemeroteca/20140526/54406528632/hiildegart-rodriguez-aurora-rodriguezparricidios-espana-ii-republica-ninos-prodigio-eugenesis.html, El País, edición digital, https://elpais.com/ccaa/2014/12/05/galicia/1417803612_746330.html 
Cuadro 3

Cuadro lógico de la logia Amor $1^{93}$

\begin{tabular}{|c|c|c|c|c|c|c|c|}
\hline Apellidos & Nombre & Simbólico & Profesión & Partido & Años & Iniciación & Grado \\
\hline Alonso López & Blanca & América & Actriz & & $1933-1935$ & $1 / 12 / 1933$ & \\
\hline Álvarez Burgos & María & & Actriz & & 1931-1939 & & 3 \\
\hline Álvarez De Ferrer & Celia & & & & 1934 & & \\
\hline Álvarez De Pool & Consuelo & Costa & Telegrafista & Republicana & 1933 & & 3 \\
\hline Berges Rabago & Consuelo & Yasnaia & & & 1932 & & \\
\hline Blanc Borel & Jeanne & & & & 1933-1934 & $1 / 12 / 1933$ & \\
\hline Burgos & Mercedes de & & & & 1934 & & \\
\hline Burgos Seguí & Carmen de & Colombine & Escritora & $\mathrm{RS}$ & 1931 & & 3 \\
\hline Burgos Seguí & Catalina de & Marianela & & & 1931-1934 & & 3 \\
\hline Carbonell Fernif & Gloria & & & & 1931 & 1931 & \\
\hline Cuarteto García & Rosario & Ariadma & Periodista & RS & 1931-1933 & & \\
\hline Durroty Mesplet & Andrea & & & & 1933 & $1 / 12 / 193$ & 3 \\
\hline Fernández & Mercedes & & & & 1931 & & \\
\hline Fiorini De Guzmán & Ana & Emma & & & 1932-1934 & & \\
\hline Fojo (Feijó) Márquez & Elena & & & & 1931 & & \\
\hline Galathi & Crisanthe & & & & & & \\
\hline Guinle De Garrido & María Teresa & & & & 1934 & $/ 6 / 1934$ & 2 \\
\hline Guinle Lasalle & María Teresa de & & & & 1933 & $1 / 12 / 1933$ & 1 \\
\hline Gutiérrez de los Ríos & María & & & & 1931-1934 & & \\
\hline Huelgas & Isabel & & & & 1933 & & \\
\hline Lissarrague & Andree de & & & & 1934 & & \\
\hline López Cumbreras & Dolores & & Sus labores & & 1934 & 1934 & \\
\hline Martín Pascua & Caridad & & & & 1934 & $/ 7 / 1934$ & \\
\hline Rodríguez Carballeira & Hildegart & Iris-egle & Derecho & PSOE/Fed & $1931-1933$ & & 4 \\
\hline Rodríguez Carballeira & Aurora & & & & 1931-1933 & & 4 \\
\hline Sánchez Pérez & Concepción & & & & 1934 & $/ 2 / 1934$ & \\
\hline Taboada Díaz De Tejada & Eulalia & & & & 1934 & & \\
\hline Fiorini De Guzmán & Ana María & & & & $1932-1934$ & 1932 & \\
\hline Ronda Pérez & Ana María & & & & 1934 & & \\
\hline
\end{tabular}

El GOE también tiene una logia de Adopción en Madrid, la logia Reivindicación, dependiente de la logia Condorcet, muy activa políticamente. Levanta columnas en 1932. Cuenta con mujeres destacadas en círculos intelectuales, sociales y políticos como Clara Campoamor $^{94}$, Esmeralda Castells, Rosario Amat, Luz Fernández, Rosalía Goy, Matilde

\footnotetext{
${ }^{93}$ Según Alonso, "Masonería y Política en Madrid", 466-467.

${ }^{94}$ Logia Reivindicación. Vocal de la Junta Central de la Liga de Madrid. Nace en Madrid el 12 de febrero de 1888. Escritora, política y defensora de los derechos de la mujer. Crea la Unión Republicana Femenina e impulsora del sufragio femenino en España. Trabaja como modista y en las oposiciones de junio de 1909 consigue plaza como auxiliar femenina del cuerpo de auxiliar de Telégrafos. En 1914 gana por oposición una plaza en el ministerio de Instrucción Pública. Es traductora de francés, auxiliar mecanógrafa en el Servicio de Construcciones Civiles y secretaria de Salvador Cánovas Cervantes, director del periódico La Tribuna. En 1924 se licencia en derecho. En 1925, se convierte en la segunda mujer en incorporarse al colegio de Abogados de Madrid. En 1929 pertenece a la Agrupación Liberal Socialista. Diputada a Cortes Constituyentes por el partido Radical. Participa en el proyecto de la Constitución defendiendo que se incluya la igualdad de derechos de la mujer, la igualdad jurídica de los nacidos dentro y fuera del matrimonio, el divorcio y el sufragio femenino. En 1934 abandona el partido Radical. Al inicio de la guerra de España se exilia en Paris. En 1955 se instala en Lausana (Suiza) donde muere el 30 de abril de 1972. CDMH Masonería B 672/4, BOSCG33 (diciembre de 1933), Francisco Ferrari Billoch, Entre masones y Marxistas. 85, Natividad Ortiz Albear, "Clara Campoamor
} 
Muñoz y María Ronda. Las dos últimas pertenecen a la Liga de la Educación y Enseñanza $(\mathrm{LEYE})^{95}$.

Se sabe que pretende trabajar en defensa de "la democracia, libertad y justicia" y que escribe al menos dos escritos, representación de su planteamiento. En el primero, considera: "[...] que a la mujer española compete desarrollar una gran actividad de estos momentos, ha editado a título de ensayo, un folleto titulado "RELIGION, FANATISMO, GUERRA, RELIGION, AMOR, FRATERNIDAD”; el segundo, distingue: “[...] dos tendencias ideológicas, por una parte, de los que permanecen mentalmente en una edad de piedra y, por otra parte, de los que por la escala ascendente están en condiciones de seguir a los grandes precursores" 96 .

El 17 de septiembre de 1932, la logia Reivindicación y la logia Condorcet obsequian al masón madrileño y teniente coronel Julio Mangada con un banquete en reconocimiento por su actuación en el llamado "incidente de Carabanchel".

La logia Reivindicación se implica con la República y sus símbolos:

En abril de 1934, se celebra un homenaje a Fermín Galán, al que presenta como mártir de la República:

Las hermanas Rosario Amat y Encarnación Chamizo [...], tomando algunos puñados de la tierra donde cayeron para siempre Fermín Galán [...], ofreciendo todo ello a su madre logia en una Tenida Blanca de grato recuerdo ${ }^{97}$.

Consuelo Bergés escribe en 1935 un libro titulado Explicación de Octubre. Historia comprimida de cuatro años de República en España. De este libro hace propaganda, Rosalía Goy del que llega a decir "que informa, define y orienta. Una exposición analítica, serena y optimista, del movimiento revolucionario, con todos sus factores, antecedentes y consecuencias inmediatas"98. En el prólogo del libro afirma: "[...] hay que dejar bien claro que España no es ni más ni menos que una gran tierra de hombres que pretenden, a veces sin saberlo, pero siempre sintiéndolo, cumplir su destino de cada minuto, conquistar su justicia de cada hora" 99 .

Por último, dentro de esta logia se produce un proceso de justicia masónica que se impone a Ana María Ronda Pérez ${ }^{100}$ derivado de la demanda presentada por Juana García

y la logia Reivindicación de Madrid", 861-865, Concha Fagoaga y Paloma Saavedra, Clara Campoamor: la sufragista española (Madrid, 2006).

${ }_{95}$ Ortiz Albear, "Las mujeres en la Masonería", 119-122, 126, Ortiz Albear, "La Logia Amor", 631.

${ }^{96}$ CDMH Masonería A 355/2; CDMH Masonería A 736/7 y Natividad Ortiz Albear: "Clara Campoamor", 861869.

${ }^{97}$ BOSCG33 (junio de 1934); CDMH Masonería B, 323/22 y Ortiz Albear, "Clara Campoamor”, 866.

${ }^{98}$ CDMH Masonería B, 155/4 y Ortiz Albear, "Clara Campoamor", 866-867.

${ }^{99}$ CDMH Masonería B, 155/4 y Ortiz Albear, "Clara Campoamor", 867.

${ }^{100}$ Logia Amor y Logia Reivindicación, grado segundo. Iniciada en la logia Amor en mayo de 1932, pero en 1934 aparece como miembro de la logia Reivindicación de Madrid, donde es expedientada. También pertenece 
del Pozo, afiliada también del taller, que la acusa de difundir secretos masónicos. Varias masonas de la logia testifican en el proceso y siguiendo su declaración se puede concluir que los enfrentamientos no son sólo masónicos, sino que están relacionados con las actividades públicas e incluso son de tipo personal. Finalmente es expulsada ${ }^{101}$.

Cuadro 4

Cuadro Lógico de la logia Reivindicación ${ }^{102}$

\begin{tabular}{|l|l|}
\hline Apellidos y nombre & Años \\
\hline Amat, Rosario & 1934 \\
\hline Campoamor Rodríguez, Clara & 1932 \\
\hline Casstells, Esmeralda & $1932-1934$ \\
\hline Chamizo, Encarnación & 1934 \\
\hline Fernandez Berbiela De Flores, Luz & 1932 \\
\hline Garcia del Pozo, Ana & 1933 \\
\hline Goy Busquets, Rosalia & 1932 \\
\hline Hidalgo, Mercedes & 1932 \\
\hline Martinez de Albacete, Isabel & 1932 \\
\hline Muñoz, Matilde & 1934 \\
\hline Ronda Pérez, Ana María & 1934 \\
\hline Salmeron, Maria Luisa P & 1932 \\
\hline Verges (Berges) & 1932 \\
\hline Rabaco, Consuelo & $1933-1934$ \\
\hline
\end{tabular}

La logia Catoniana, también tiene una cámara de Adopción en la que consta Ana María Fiorini de Guzmán, iniciado en 1932 y de la que hay datos entre 1932 y $1934^{103}$.

El tema de masonería femenina está vigente incluso durante la guerra de España. En la logia Accidental núm. 1 de Valencia en 1937 se trata el tema de la creación de una logia de Adopción, puesto que hay masonas madrileñas que a consecuencia de la guerra y el traslado del gobierno a Valencia residen en esa ciudad y masonas valencianas que no pueden reunirse por no haber en Valencia ninguna logia de Adopción ${ }^{104}$.

\section{La masonería mixta}

En el siglo XIX, como se sabe, hay mujeres dentro de logias masculinas que hace pensar que en la práctica son mixtas. De hecho, las primeras masonas españolas de las que

\footnotetext{
a Liga de Educación y Enseñanza donde ocupa el cargo de Tesorera. CDMH Masonería A 736/7 - Logia Reivindicación, CDMH Masonería B 447/6, BOGLE (abril-mayo de 1932), Ortiz Albear, Las mujeres en la Masonería, 121 y Ortiz Albear. "La Logia Amor de Madrid", 638.

${ }^{101}$ CDMH Masonería B 447/6 y Ortiz Albear, "Clara Campoamor", 866-867.

${ }^{102}$ Según Alonso, "Masonería y Política en Madrid", 472.

${ }^{103}$ CDMH Masonería A 751/1.

${ }^{104}$ Sampedro Ramo, "La aplicación de la ley sobre represión de la Masonería y del Comunismo en el país valenciano", 299.
} 
hay noticias son Amalia Antigüedad, simbólico Cesárea, grado tercero y Elvira Chacel, simbólico Mariana Pineda, grado tercero que en 1871 son dadas de baja de la logia Comuneros de Castilla del Gran Oriente de España ${ }^{105}$. También se encuentra en esta logia a Emilia Martín Herrería, simbólico Esther, grado 18 en 1892, esposa de Nicolás Díaz y Pérez, simbólico Viriato ${ }^{106}$. En la logia Fraternidad Ibérica a Julia Rubio y Guillén, condesa de Apratxin, simbólico Budha, esposa de masón, que se inicia en esta logia en 1880, siendo la primera mujer iniciada en el regular y conservador GONE.

${ }^{105}$ Ferrer Benimeli, "Las mujeres y la masonería”, 164.

${ }^{106}$ Ferrer Benimeli, "Las mujeres y la masonería", 165 y Esteban Cortijo coord., Masonería y Extremadura (Cáceres: Edición de la Caja de Ahorros de Extremadura y el Ateneo de Cáceres, 2008), 123-132. 
Cuadro 5

Mujeres en logias madrileñas en el último tercio del siglo XIX ${ }^{107}$

\begin{tabular}{|c|c|c|c|c|}
\hline Apellidos & Simbólico & Años masónicos & Grados & Logia \\
\hline López de Ayala Molero, Angela & & $1888-1895$ & 3 & Amor y Ciencia \\
\hline Montagud, Adela & & 1888 & 1 & Amor y Ciencia \\
\hline Dupont, Luisa & & 1887 & 2 & Caballeros de Oriente \\
\hline Aldao y Sarmiento, Antonia & Victoria & 1892 & 4 & Comuneros de Castilla \\
\hline Antigüedad, Amalia & Cesárea & 1871 & 31 & Comuneros de Castilla \\
\hline Armedo de Aldao, Amaría & Isis & 1892 & 9 & Comuneros de Castilla \\
\hline Blasco Carreras, Dolores & Guadalquivir & 1892 & 1 & Comuneros de Castilla \\
\hline Chacel, Elvira & Mariana pineda & 1871 & 3 & Comuneros de Castilla \\
\hline Diaz Martin, Alicia & Democracia & 1895 & lowatona & Comuneros de Castilla \\
\hline Fernández Ceballos, Soledad & Ceres & 1892 & 1 & Comuneros de Castilla \\
\hline López de Ayala Molero, Ángeles & & $1888-1895$ & 3 & Comuneros de Castilla \\
\hline López Rosso, Luisa & Agustina de Aragón & 1892 & 1 & Comuneros de Castilla \\
\hline Martínez de la Herrería, Emilia & Esther & 1871-1895 & 18 & Comuneros de Castilla \\
\hline Martínez, María & Judit & 1891 & & Comuneros de Castilla \\
\hline Martínez de Das, Antonia & Judit & 1892 & 18 & Comuneros de Castilla \\
\hline Muñoz Caravaca De Moya, Isabel & Justicia & 1892 & 1 & Comuneros de Castilla \\
\hline Rosso, Concepción & Juana de Arco & 1892 & 1 & Comuneros de Castilla \\
\hline Marchate de Payno, Leandra & Leandra & 1888 & & Constancia \\
\hline López de Ayala y Molero, Ángela & Ángela & 1888 & & Constancia \\
\hline Antón Rodríguez, María & Caridad & $1885-1886$ & 4 & Hijos del Progreso \\
\hline Bustamante, Carmen & Luz & $1885-1886$ & 12 & Hijos del Progreso \\
\hline Catalán, Eugenia & Mariana Pineda & 1885 & & Hijos del Progreso \\
\hline Ferrandis (Fernández), Vicenta & Juana de Arco & Antes 1885 & 2 & Hijos del Progreso \\
\hline García, Carlota & & Antes de 1885 & & Hijos del Progreso \\
\hline García Broca, Tomasa & & 1885 & 3 & Hijos del Progreso \\
\hline García Obispo, Luisa & & Antes de 1885 & & Hijos del Progreso \\
\hline García Obispo, Josefa & & Antes de 1885 & & Hijos del Progreso \\
\hline Landeita y García, Aurora & & 1885 & & Hijos del Progreso \\
\hline Llopart, Esperanza & $\mathrm{Fe}$ & Antes $1885-1886$ & & Hijos del Progreso \\
\hline Menéndez, Ana María & & Antes de 1885 & & Hijos del Progreso \\
\hline Sira, Amparo & Agustina de Aragón & 1889 & & Hijos del Progreso \\
\hline Úbeda Torbo, Nieves & & 1885 & & Hijos del Progreso \\
\hline Antón Rodríguez, María & Caridad & $10 / 12 / 1886$ & 4 & Legalidad \\
\hline Bustamante, Carmen & Luz & $14 / 06 / 1886$ & 12 & Legalidad \\
\hline Fernández, Adoración & Ester & $10 / 12 / 1886$ & 2 & Legalidad \\
\hline Fernadis, Vicenta & Juana de arco & $14 / 06 / 1886$ & 2 & Legalidad \\
\hline Llopart, Esperanza & $\mathrm{Fe}$ & $10 / 12 / 1886$ & 3 & Legalidad \\
\hline Navarro, Emilia & Judit & $14 / 06 / 1886$ & 2 & Legalidad \\
\hline Perero, Leonarda & Orense & $10 / 12 / 1886$ & 3 & Legalidad \\
\hline Sánchez Martín, Suceso & Rebeca & $10 / 12 / 1886$ & 3 & Legalidad \\
\hline Martínez, Concepción & & 1891 & & Acacia \\
\hline Martínez, Josefa & & 1891 & & Acacia \\
\hline Menéndez, Ana María & & $1886-1892$ & & Acacia \\
\hline Perrot Menéndez, Ana & & 1891 & & Acacia \\
\hline Aguilera, Concepción & & $15 / 5 / 1895$ & 2 & Puritanos \\
\hline Jiménez de Aguilera, Blanca & & $15 / 5 / 1895$ & 2 & Puritanos \\
\hline Jiménez de Aguilera, Elena & & $15 / 5 / 1895$ & 2 & Puritanos \\
\hline Jiménez de Aguilera, Rosalía & & $15 / 5 / 1895$ & 2 & Puritanos \\
\hline
\end{tabular}

${ }^{107} C D M H$ Masonería A 733/5; $C D M H$ Masonería A 733/23 y 565; $C D M H$ Masonería A 734/18 y 19; $C D M H$ Masonería A 733/10; $C D M H$ Masonería A 736/18; CDMH Masonería A 733/18, CDMH Masonería A 735/15; $C D M H$ Masonería A 554/3; CDMH Masonería a 736/5. 
En el cuadro anterior hay que añadir a Natividad López Polo que se encuentra entre 1890 y 1891 en la logia Hijos del Trabajo en Valdemorillo (Madrid).

En 1885, Caballero de Puga, en el Gran Capítulo Provincial de Barcelona, afirma que las mujeres están en la plenitud de sus derechos masónicos; y, por tanto, pueden ser iniciadas en "el simbolismo heredado de la masonería operativa", aconsejando que sean aceptadas cuando tengan más de veintitrés años y sean "preferentemente esposa, hija, hermana o viuda de masón". Cambiará de opinión, y 1891 siendo Gran Secretario del GONE firmará el decreto y reglamentos sobre las logias de Adopción y en 1892 publicará un ritual titulado "Francmasonería femenina. Grado Primero del Rito de adopción o de señoras creado como rama especial y completamente separado de la Francmasonería Masculina"108.

Ya en el siglo veinte entre 1922 y 1927 hay constancia de la existencia, primero de un triángulo y después una logia denominada San Albano núm. 803 del DH ${ }^{109}$. Logia mixta de origen, siendo la primera organización fundada en España y la única organización que trabaja en Madrid representante de esta Obediencia durante el periodo de estudio. La mayoría de sus miembros pertenecen a la Teosofía.

El 30 de marzo de 1923, la Sección Administrativa del Rito se dirige a Treviño informándole que hay masonas que han abandonado sus obediencias y quieren unirse al Derecho Humano. Consideran que las hermanas iniciadas en el rito de Adopción no son masonas regulares, por tanto "no pueden ser recibidas como visitadoras, ni ser afiliadas", para serlo deben ser iniciadas de nuevo ${ }^{110}$. En definitiva, no reconocen la iniciación en el rito de Adopción.

De los miembros que se conocen de la logia San Albano, nueve son mujeres ${ }^{111}$ :

Cuadro 6

Logia San Albano ${ }^{112}$

\begin{tabular}{|l|c|c|c|l|}
\hline Apellidos y nombre & GRADO & AÑOS & TEOSÓFIA & INICIACIÓN \\
\hline Armisen y Tomas, Julia & 2 & $1924-1925$ & $\mathrm{Si}$ & $19 / 06 / 1921$ \\
\hline Fernández Guerrero, Rosario & 3 & 1924 & $\mathrm{Si}$ & \\
\hline Gutiérrez de Joseph, Guadalupe & 18 & $1924-1925$ & $\mathrm{Si}$ & \\
\hline Garro de Velasco, Sofía & 2 & 1924 & $\mathrm{Si}$ & \\
\hline Gil Gil, Hilaria & 1 & 1925 & $\mathrm{Si}$ & 1925 \\
\hline Guerrero, Rosario & 18 & $1924-1925$ & $\mathrm{Si}$ & \\
\hline Olano Rodríguez, María Rebeca & 1 & 1925 & $\mathrm{Si}$ & 1925 \\
\hline Guyard, Celine & 1 & 1924 & $\mathrm{Si}$ & \\
\hline Borillo, Juana & 1 & 1924 & $\mathrm{Si}$ & \\
\hline
\end{tabular}

${ }^{108}$ Ferrer Benimeli, "Las mujeres y la masonería", 169-171, 179.

${ }^{109}$ CDMH Masonería A 736/10 y María José Lacalzada de Mateo. El Cimiento Mixto de Masonería. El Derecho Humano en España (1893-1963) (Zaragoza: Fundación Maria Deraismes, 2007), 139-143.

${ }^{110}$ CDMH Masonería A 736/10.

${ }^{111}$ CDMH Masonería A 736/10 y Vicente PENALVA MORA, "El Orientalismo en la Cultura Española en el primer tercio del s. XX. La sociedad Teosófica Española (1888-1840)" (Tesis doctoral en Historia Comparada, Política y Social, Universidad Autónoma de Barcelona, 1913.

${ }^{112}$ Según Alonso, "Masonería y Política en Madrid", 478. 


\section{Conclusiones}

1. La mujer es excluida de la masonería porque no es considerada libre por su dependencia al hombre que la tutela.

2. Desde finales del siglo XVIII en Francia, se ve la necesidad de buscarle un sitio dentro de la Orden.

3. En Madrid, a partir del Sexenio Revolucionario se encuentran las primeras mujeres en las logias. Hay mujeres en logias teóricamente masculinas que nos hace pensar que éstas en la práctica son mixtas.

4. El rito, las cámaras y las logias de Adopción nacen para evitar la iniciación de mujeres en logias masculinas, teniendo un carácter auxiliar, no permitiendo que trabajen a nivel de igualdad.

5. Las masonas mantienen un posicionamiento anticlerical y feminista. Pretenden que la mujer participe en la vida pública. Defienden el pacifismo, la democracia, la libertad, la justicia y la beneficencia.

6. Trabajan el Rito Escocés Antiguo y Aceptado cuando participan en las logias masculinas o mixtas; y en el Rito de Adopción cuando trabajan en las logias de Adopción.

7. Entre 1869 y 1900 encontramos mujeres en las logias masculinas de Madrid: Amor y Ciencia, Caballero de Oriente, Comuneros de Castilla, Constancia, Hijos del Progreso, Legalidad, Acacia, Puritanos e Hijos del Trabajo (Valdemorillo); en las logias de Adopción: Minerva, Hijas de los Pobres, Hijas del Sol, Hijas de Memphis, Hijas del Progreso, Hijas del Sol y Porvenir; y en las cámaras de Adopción de las logias Ibérica núm. 7 y Progreso núm. 88.

8. Entre 1901 y 1923, existe una cámara de Adopción dependiente de la logia Ibérica; una logia de Adopción, la Paz núm. 8, dependiente la logia Ibérica; y una cámara de Adopción en la logia Condorcet.

9. Entre 1923-1931, no hay constancia de presencia femenina en la masonería de Adopción y sí, en el triángulo y después logia San Albano del DH (1922-1927).

10. En el periodo republicano hay dos logias de Adopción, una en la GLE, la logia Amor; y otra, en el GOE, la logia Reivindicación.

11. Por último, hay que señalar que, durante el periodo a estudio, hay presencia de noventa y ocho mujeres frente a los tres mil quinientos cuarenta y cinco hombres dentro de la masonería madrileña, lo que indica que ésta es una organización masculina donde la mujer tiene una presencia testimonial, pero no por ello, poco importante. 


\section{Fuentes}

AHD Madrid Sumario 31087 Legajo 1985.

BOGOE 1890, 1892, 1907, 1911, 1918.

BOGLE 1931-1933.

BOSCG 33 1923, 1933-1934.

Boletín Oficial del GODE 1880.

Centro Documental de Memoria Histórica, Masonería A y B.

Latomia 1931.

Vida Masónica 1926.

\section{Bibliografía}

Aragüés Estragués, Rosa. "Victoria Kent y el Tribunal de Represión de la Masonería y el Comunismo". En La masonería hispano-lusa y americana. De los absolutismos a las democracias (1815-2015). Coordinado por José Miguel Delgado Idarreta e Yván Pozuelo Andrés. Oviedo: Universidad de Oviedo, 2017.

Ballesteros García, Rosa. "Las distracciones misteriosas: Colombine y la masonería portuguesa". Revista de Ciencias Sociales 5 (febrero 2005): 1-21.

Estatutos y Reglamento Generales del Grande Oriente Español. Sevilla: tipografía Minerva, 1932.

Janet Burke y Jacob Margaret. Les premiéres francs-maconnes au siécle des Lumiéres. Burdeos: Presses Universitaires. 2010.

Libertad Morte. "La mujer en la masonería". Revista Historia 16 (noviembre de 1977).

Espinosa Gutiérrez, Jesús. "Feminismo de hombres en la masonería y el librepensamiento español (1868-1920)". En La masonería hispano-lusa y americana. De los absolutismos a las democracias (1815-2015). Coordinado por José Miguel Delgado Idarreta e Yván Pozuelo Andrés. Oviedo: Universidad de Oviedo, 2017.

Fagoaga, Concha y Paloma Saavedra. Clara Campoamor: la sufragista española. Madrid, 2006

Ferrari Billoch, Francisco. Entre masones y Marxistas. Revelación de la masonería femenina Madrid: Ediciones Españolas, 1939.

Ferrer Benimeli, José Antonio. Exposición: La masonería española. 1728-1939. Alicante: Instituto Juan Gil-Albert, Caja de Ahorros Provincial de alicante, Diputación de Alicante, 1989.

Ferrer Benimeli, José Antonio. "Las mujeres y la masonería española en el siglo XIX. REHMLAC+ 10, no. 2 (diciembre 2018-mayo 2019): 157-193. https://revistas.ucr.ac.cr/index.php/rehmlac/article/download/12185/11468/ 
Lacalzada de Mateo, María José. El Cimiento Mixto de la Masonería. El Derecho Humano en España (1893-1963). Zaragoza: Fundación Maria Deraimes, 2007.

Folguera Crespo, Pilar. "Las mujeres en la España contemporánea". En Historia de las Mujeres en España. Madrid: Síntesis, 1997.

Lacalzada de Mateo, María José. 'La Mitad Femenina 'para' la masonería y ‘en’ masonería (1868-1936). Balance y perspectiva”. Revista Investigaciones históricas: Época $\begin{array}{lllll}\text { moderna } & y & \text { Contemporánea, } & 23 & \text { (2003): }\end{array}$ https:/core.ac.uk/download/pdf/61558786.pdf

Lacalzada de Mateo, María José. Mujeres en masonería. Antecedentes históricos entre las luces y las sombras (1868-1938). Premià de Mar: Clavell, 2006.

Masonería Femenina. Madrid: Ediciones Toledo, 1942

Ortiz Albear, Natividad. "Clara Campoamor y la logia Reivindicación de Madrid". En La masonería hispano-lusa y americana. De los absolutismos a las democracias (18152015). Coordinado por José Miguel Delgado Idarreta e Yván Pozuelo Andrés. Oviedo: Universidad de Oviedo, 2017.

Ortiz Albear, Natividad. "La Logia Amor de Madrid: una logia femenina en la II República". En La masonería española en el 2000. Una revisión Histórica. Coordinado por José Antonio Ferrer Benimeli. Zaragoza: Gobierno de Aragón, 2001.

Ortiz Albear, Natividad. Las mujeres en la Masonería. Málaga: Atenea, 2005.

Ortiz Albear, Natividad. "La integración de las mujeres en la masonería española a través del Rito de adopción (1868-1939)". Revista Studia Histórica. Historia Contemporánea 23, (2005). http://revistas.usal.es/index.php/0213-2087/article/view/6024/6045

Ortiz Albear, Natividad. Mujeres masonas en España (1868-1939). Santa Cruz de Tenerife: Ediciones Idea, 2007

En Natividad Ortiz Albear. "Las Mujeres en la Masonería Española (1868-1939)". REHMLAC 4, no. 2, (diciembre 2012-abril 2013): 76-88. https://revistas.ucr.ac.cr/index.php/rehmlac/article/download/12185/11468/

Penalva Mora, Vicente. "El Orientalismo en la Cultura Española en el primer tercio del s. XX. La sociedad Teosófica Española (1888-1840)”. Tesis doctoral en historia comparada, política y social, Universidad Autónoma de Barcelona, 2013.

Presmanes García, Rosa Elvira. La masonería femenina en España. Dos siglos de historia por la igualdad. Madrid: Catara, 2012

Randouyer, Françoise. "Presencia femenina precoz en las logias españolas (1868-1898)". En La masonería española en el 2000. Una revisión Histórica. Coordinado por José Antonio Ferrer Benimeli. Zaragoza: Gobierno de Aragón, 2001.

Ritual de la aprendiza masona del Rito de Adopción. Madrid: 1906

Ritual de la aprendiza masona del Rito de Adopción del GOE. Madrid: 1932

Ruiz, J “Alvar Fáñez” Y Ruiz C “Algebra”. Estatutos y Reglamentos de la Masonería de Adopción. Biblioteca Masónica. Madrid: Imprenta de Ricardo Rojas, s/f. 
Salmón Moviola, Olivia. Los masones de Madrid (1939). Repertorio de miembros, acción cultural y comunicación social. La Laguna: Editorial Relax Color (CD), 2006.

Sampedro Ramo, Vicent. "La aplicación de la ley sobre represión de la Masonería y del Comunismo en el país valenciano: Los Masones de Alicante y Castellón (1938-1963). Tesis de doctorado en historia, Universitat Jaume I de Castellón de la Plana, 2016.

Según Alonso, Manuel. "Masonería y Política en Madrid (1900-1939)". Tesis de doctorado en historia e historia del arte y territorio, UNED, 2018.

Sevillano, Antonio. "Catalina de Burgos, Báculo de Colombine”, Revista Colombine. Agrupación Especial Carmen de Burgos del Ateneo de Madrid (2019): 1-5. 